\title{
Five ICGA Events in Leiden, the Netherlands: July, 2017
}

The Board of the ICGA

Five ICGA events will take place, July 1-7, 2017 in Leiden, the Netherlands, in the Snellius building of the Leiden University, Niels Bohrweg 1, 2333 CA Leiden, the Netherlands. We are grateful to LIACS and the Faculty of Science and the ICT Shared Service Centre (ISSC) of Leiden University for their offer to sponsor and organize five events in cooperation with the ICGA, viz. the 23rd WCCC, the 7th WCSC, the 2017 World Computer Chess Blitz Championship, the 20th Computer Olympiad, and the 15th Advances in Computer Games Conference (ACG2017). Below we provide rules and information on these five events.

\section{RULES FOR THE 23rd WORLD COMPUTER-CHESS CHAMPIONSHIP}

The 23rd World Computer-Chess Championship will take place from July 1 - July 7, 2017 in Leiden, the Netherlands, in the Snellius building of the Leiden University, Niels Bohrweg 1, 2333 CA Leiden, the Netherlands. Here we recall that the Maastricht Triennial Meeting in 2002, i.e., the first ICGA meeting (instead of ICCA), decided that the WCCC should be held annually without distinguishing any type of machines. The observation was clear: all kinds of differences between microcomputers, personal computers, "normal" computers, and supercomputers were in some sense obsolete and the classification thus was considered artificial. So was the division into the classes of single processors and multiprocessors.

Another division considered obsolete in the competition since 2002 is that between amateur, semiprofessional, and professional. In 2015 we also abandoned the differences in payments and made the

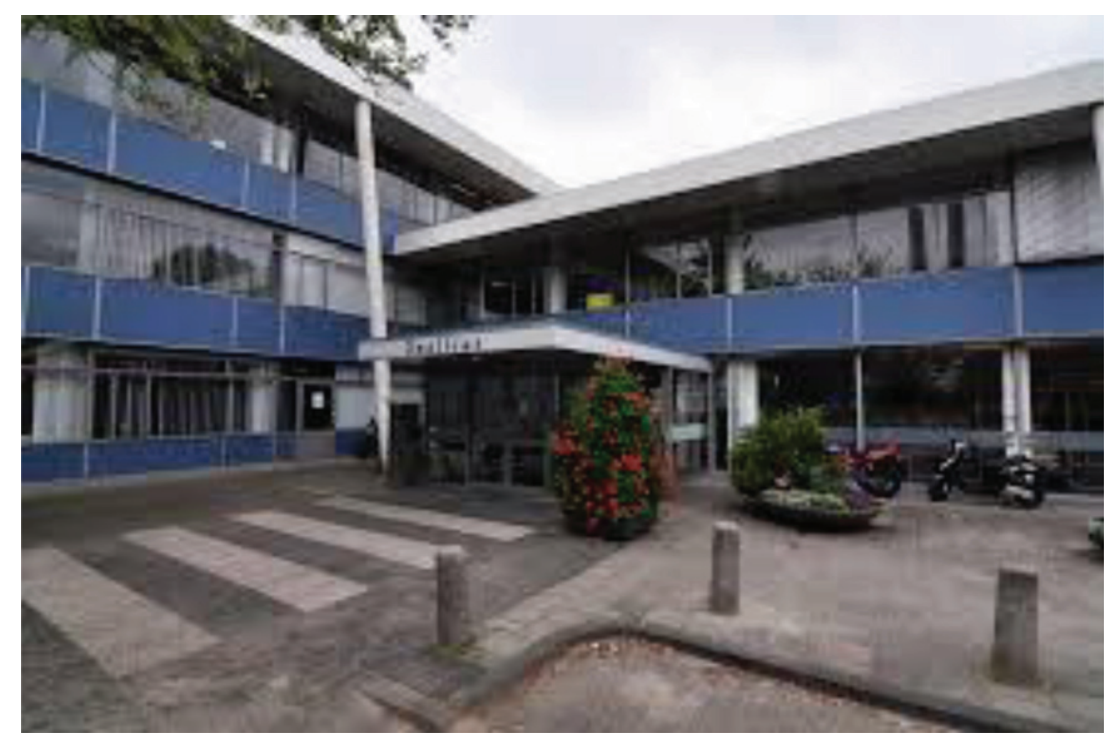

Fig. 1. The Snellius building. 
subscription for participants equal for all types of human programmers and their programs (for all games). The only prerequisite is originality. See rule 2 of the 23rd World Computer-Chess Championship which holds for all games and all types of competitions in Leiden 2017.

Following the survey conducted amongst chess programmers after the WCCC tournament in Pamplona, the ICGA announced the inauguration of a new tournament for 2010 and subsequent years - The World Chess Software Championship (WCSC).

Below we provide the rules for the 23rd World Computer-Chess Championship, for the 2017 World Chess Software Championship, for the 2017 World Computer Chess Blitz Championship, and for the 20th Computer Olympiad. It was agreed at the Maastricht meeting that from the 13th World ComputerChess Championship onwards the Shannon Trophy will be awarded annually (if it were possible to organize the tournaments). The original trophy is kept at ICGA headquarters in Leiden, and each year a replica of the trophy is presented on a permanent basis to the World Computer-Chess Champion team. A trophy will be given each year to be retained by the winner of the World Chess Software Championship. The years 2012 and 2014 were in all aspects an exception since the ICGA was unable to find a sponsor for the events.

For the WCCC and the WCSC, we have split the rules into two sections of general rules and two sections of tournament rules.

\section{GENERAL RULES - WORLD COMPUTER-CHESS CHAMPIONSHIP (WCCC)}

1. The World Computer-Chess Championship 2017 is the $23 \mathrm{rd}$ in a series of World Computer-Chess Championships. It follows the tournament rules given below.

2. The tournament will be an all-play-all tournament if the number of participants is twelve or below. The provisional playing schedule is announced on the ICGA website. If the number of participants is six or below a double all-play-all tournament will be considered. If the number of participants is higher than twelve, it will be an 11-round Swiss tournament.

3. The winner of the Tournament will be awarded (1) a replica of the Shannon Trophy; and (2) the title of World Computer-Chess Champion 2017. No other titles following from the results of this tournament will be awarded. (Hence, no Amateur title, no Microcomputer title, and no single-processor title, as well as no multi-processor title.) No prize money is available at the moment but additional sponsors are welcome.

4. Unless otherwise specified, the rules of play are identical to the FIDE laws of Chess, the latest release. In particular this holds for claiming a draw with respect to the three-times-repetition rule (see ICGA Journal, Vol. 28, No. 1, News section). If a point is in question, the Tournament Director has the right to make the final decision (with due respect to the Committee of Appeal).

5. Each game is played on a chessboard with a chess clock provided by the Tournament Committee.

6. At the end of each game, both teams are required to send in a game listing to the Tournament Director in electronic (PGN) form. In case of DGT boards only by request of the Tournament Director.

7. The Tournament Director will be Jan Krabbenbos. He has the power to designate assistants with the appropriate power to decide in cases of dispute. The assistant Tournament Director will be Professor H. Jaap van den Herik.

8. In the event of any rule disputes, or changes necessitated by circumstances at the time, the Tournament Director's decision shall be final (with due respect to the Committee of Appeal). 
9. The members of the Appeal Committee will be agreed upon during the participants' meeting on July $1,2017$.

10. The entry fees for the 23rd WCCC (exclusive of membership fee of the ICGA for 2017 for at least one person) are $€ 50$.

Entry forms are available at www.icga.org.

The acceptance or rejection of an entry will be determined by the ICGA President in consultation with the Tournament Director and the assistant Tournament Director on May 15, 2017. Applicants who apply to register after May 15 will be notified as soon as possible regarding the acceptance or otherwise of their application.

A participant is expected to be an ICGA member (€40). Deadline early registration: May 15, 2017. Any entry received after May 15, 2017 will be subject to a penalty fee, doubling the above fee. Website: www.icga.org.

\section{GENERAL RULES - WORLD CHESS SOFTWARE CHAMPIONSHIP (WCSC)}

1. The World Chess Software Championship 2017 is the 7th in a series of World Chess Software Championships. It follows the tournament rules given below.

2. The tournament will be an all-play-all tournament if the number is between 5 or 10 . The provisional playing schedule is announced on the ICGA website. If the number is four or less a double all-play-all tournament is played. If the number of participants is above 10 the tournament will be a 9-round Swiss tournament.

3. The winner of the Tournament will be awarded (1) a trophy, for keeping permanently; (2) the title of World Chess Software Champion 2017. There is no cash prize.

4-9. Identical to the General Rules of the WCCC.

10. The entry fees for the WCSC (exclusive of membership fee of the ICGA for 2017 for at least one person) are $€ 50$ if it is the first subscription; if the program is participating in the WCCC then it is $€ 25$.

Entry forms are available at www.icga.org.

The acceptance or rejection of an entry will be determined by the ICGA President in consultation with the Tournament Director and the assistant Tournament Director on May 15, 2017. Notification of acceptance will be given as soon as possible, as per the conditions for the WCCC.

A participant is expected to be an ICGA member (€40). Deadline early registration: May 15, 2017. Any entry received after May 15, 2017 will be subject to a penalty fee, doubling the above fee. Website: www.icga.org.

\section{3rd WORLD COMPUTER-CHESS CHAMPIONSHIP TOURNAMENT RULES}

Each entry is a computing system and one or more humans who programmed it. In the computer system there is no restriction on the hardware. At least one of the program developers should attend the 
WCCC to operate the program, otherwise (i.e., for operators who are not developers of the program they are operating) the entry fee for the program is doubled.

Each program must be the original work of the entering developers, possibly with the inclusion of game playing code and/or data from other sources for which the entering developers have a legal right of use. Developers whose code is derived from or includes (1) game-playing code; and/or (2) data written by others, must name (a) all the other developers of whom they are aware; and (b) the source of such code and/or data, in their tournament registration details.

Programs which are discovered to be undeclared derivatives of others may be designated invalid by the Tournament Director if he is convinced, after seeking advice if he feels that to be necessary, that the closeness of derivation is of such a level as to constitute unfair competition. A listing and an executable version of all game-related code and data running on the system must be available on demand to the Tournament Director prior to the start of and during the tournament. The Tournament Director has the right to submit the executable version of a program for testing for similarity with other known programs, and/or to submit the listing to an expert or experts of his choosing for examination, also to determine similarity. Under all circumstances the Tournament Director will take all reasonable steps to ensure that any such listing and/or executable are treated as being strictly confidential.

The entering developers must keep a copy of the source code of their entry until at least one year following the date of conclusion of the tournament, in order to be able to respond accurately to any questions about the source code that might be raised after the event by the Tournament Director.

Participants are required to attend an organizational meeting on July 1, 2017 prior to the start of the tournament for the purpose of officially participating in the tournament. Operational rules (such as members of the Committee of Appeal) will be finalized at that meeting.

The format of the tournament follows from rule 2 of the General Rules (WCCC). The rate of play will generally be determined by the Tournament Director according to the number of programs entered and any other relevant factors. The 23rd World Computer-Chess Championship (WCCC) is assumed to be an all-play-all tournament in which the rate of play will be all moves in 1 hour 45 minutes plus an increment of 15 seconds per move. The increment starts at move 1, i.e., the clock should be used during opening-book play.

An operator may ask the Tournament Director to stop clocks at most twice during a game because of hardware problems or network problems. The operator can ask the Tournament Director for permission to restart the program. When restarting after a failure of any kind, the operator must reset all parameters to their values at the time the game was interrupted. Play must resume after at most a fifteen-minute delay. If operators using a remote computer can clearly establish that the network problems are not in their own computing system, but in the communication network, the Tournament Director can permit additional delay.

An operator error made when starting a game or in the middle of a game can be corrected only with the approval of the Tournament Director. If an operator enters an incorrect move, the Tournament Director must be notified immediately. Both clocks will be stopped. The game must then be backed up to where the error occurred. Clocks will be corrected and the settings at the time when the error occurred will be reinstated using whatever information is available. Both sides may then adjust their program parameters with the approval of the Tournament Director. The Tournament Director may allow certain program parameters to be changed. 
All monitors must be positioned so that the operator's activities are clearly visible to the opponent. An operator may only: [a] enter moves, [b] respond to a request from the computer for clock information, and [c] under supervision of the (assistant) Tournament Director synchronize the computer clock to the normal chess clock. Misuse of this rule will be punished by the Tournament Director. If an operator needs to enter other information, it must be approved ahead of time by the Tournament Director. The operator may not query the system to see if it is alive without the permission of the Tournament Director.

A team must receive permission from the Tournament Director to change from one computing system to another.

Tie-breaking: (a) if precisely two participants are tied for first place, two play-off games of one hour per side are to be played. At the longest, such a match may take four hours. Should that match be drawn, then one sudden death game should be played (White 12 minutes, Black 10 minutes); (b) if more than two participants have an equal number of points, a tie-ranking order is defined as follows. The dominant ranking is by the sum of the opponents' scores. If there is still a tie, the sum of the respective programs' cumulative scores after each round (i.e., score after round- $1+$ score after round- $2+\ldots .+$ score after last-round) will be used; (c) the two participants ranked most highly by the tie-ranking order in (b) will then play off as in (a). An analogous tie-breaking procedure applies for establishing the second place and, if necessary, the third place.

For the play-off procedure for the first place as given in rule 9, the color assignment is as follows. In the first match game the colors are reversed with respect to the game played in the tournament. In the sudden-death game the following rules apply: (a) if possible, the colour division in the tournament plus the sudden-death game will be equalized. If this is impossible then (b) the colors of the game played in the tournament will be adopted since in the tournament White has had a slight advantage and now in the play-off this advantage will go to Black. Play-off procedures for the second (and for the third) place follow the analogous colour-assignment procedure.

\section{WORLD CHESS SOFTWARE CHAMPIONSHIP TOURNAMENT RULES}

The tournament rules for this championship are the same as for the WCCC with due substitutions and except for the following.

Rule 4 should be read as follows.

"The format of the tournament is assumed to be an all-play-all tournament (depending on the number of participants, see rule 2 of the General Rules WCSC), in which the rate of play will be all moves in 45 minutes plus an increment of 15 seconds per move. The increment starts at move 1, i.e., the clock should be used during opening-book play."

Rule 9 should be read as follows.

"Tie-breaking: (a) if precisely two participants are tied for first place, two play-off games of 45 minutes plus an increment of 15 seconds per move are to be played. At the longest, such a match may take four hours. Should that match be drawn, then (b) if more than two participants have an equal number of points, a tie-ranking order is defined as follows. The dominant ranking is by the sum of the opponents' scores. If there is still a tie, the sum of the respective programs' cumulative scores after each round (i.e., score after round- $1+$ score after round- $2+\ldots$. + score after last-round) will be used; (c) the two participants ranked most highly by the tie-ranking order 
Table 1

\begin{tabular}{llll}
\hline Abalone & Computational Pool & Go $9 \times 9$ & Phantom Go \\
Amazons & Connect 6 & Havannah & Poker \\
Arimaa & Diplomacy & Hex & Scrabble \\
Backgammon & Dominoes & Kriegspiel & Stratego \\
Bao & Dots and Boxes & Lines of Action & Shogi \\
Bridge & $10 \times 10$ Draughts & Mahjong & Shogi $5 \times 5$ \\
Chinese Chess & Ein Stein Wurfelt Nicht & NoGo & Surakarta \\
Chinese Dark Chess & Gipf & Nonogram & \\
Chu Shogi & Go & OCTI & \\
Clobber & Go $13 \times 13$ & Othello & \\
\hline
\end{tabular}

in (b) will then play off as in (a). An analogous tie-breaking procedure applies for establishing the second place and, if necessary, the third place."

\section{WORLD COMPUTER CHESS BLITZ CHAMPIONSHIP}

The tournament rules for this championship are the same as for the WCCC with due substitutions and except for the following.

The tournament will be a double round all-play-all tournament if the number of participants is 6 or below.

The time limit for the 2016 World Computer Chess Blitz Championship will be 5 minutes $(+5 \mathrm{~s}$ per move) per program per game.

An operator error (e.g., playing an illegal move) immediately leads to losing the game.

Hardware problems and network problems are to be remedied in the allotted time frame.

The entry fee for the Blitz Championship is free provided that the program participates in either the WCCC or the WCSC.

Moreover, the rules 4, 5, 6, 7. 8, and 10 of the WCCC apply.

\section{THE 20th COMPUTER OLYMPIAD}

The Leiden Centre of Data Science (LCDS) is enabling the organization of the Computer Olympiad, i.e., the 20th Computer Olympiad (CO) (July 1 - July 7). Location: the Snellius Building, Niels Bohrweg 1, 2333 CA Leiden, the Netherlands.

The Computer Olympiad is a multi-games event in which all of the participants are computer programs. The purpose is to find the strongest programs at each of the games, partly as an academic exercise and partly because the competitions are fun. In Table 1 we mention 37 different games for which a program can be submitted to the Olympiad.

We are willing to host more games, such as Ataxx, Dvonn, Light up, Mediocrity, Onyx, Tamsk, TwixT, and Zèrtz, but we do not know of the existence of adequately playing programs. We are 
awaiting suggestions and proposals of programmers before we include them in the official list given in Table 1.

For each game, a tournament will take place provided that at least two programs enter the tournament for that particular game. Gold, Silver and Bronze medals will be awarded to the leading programs in each tournament. Games played at the Computer Olympiad:

\section{RULES AND GENERAL RULES - COMPUTER OLYMPIAD}

The computer Olympiad 2017 is the 20th in a series of Computer Olympiads. It follows the tournament rules given below.

Each program must be the original work of the entering developers, possibly with the inclusion of game playing code and/or data from other sources for which the entering developers have a legal right of use. Developers whose code is derived from or includes (1) game-playing code and/or (2) data written by others, must name (a) all the other developers of whom they are aware and (b) the source of such code and/or data, in their tournament registration details.

Programs which are discovered to be undeclared derivatives of others may be designated invalid by the Tournament Director if he is convinced, after seeking advice if he feels that to be necessary, that the closeness of derivation is of such a level as to constitute unfair competition. A listing and an executable version of all game-related code and data running on the system must be available on demand to the Tournament Director prior to the start of and during the tournament. The Tournament Director has the right to submit the executable version of a program for testing for similarity with other known programs, and/or to submit the listing to an expert or experts of his choosing for examination, also to determine similarity. Under all circumstances the Tournament Director will take all reasonable steps to ensure that any such listing and/or executable are treated as being strictly confidential.

The entering developers must keep a copy of the source code of their entry until at least one year following the date of conclusion of the tournament, in order to be able to respond accurately to any questions about the source code that might be raised after the event by the Tournament Director.

The entry fee for the Olympiad tournaments is as follows: $€ 50$ for the first game and $€ 25$ for each subsequent game (exclusive ICGA membership).

For instance, when subscribing for more than one Go or Shogi tournament the participant should pay for one tournament $€ 50$, the others are then $€ 25$.

A participant is expected to be an ICGA member (€40). Deadline early registration: May 15, 2017. Any entry received after May 15, 2017 will be subject to a penalty fee, doubling the above fee. Website: www.icga.org.

The Tournament Directors of the Computer Olympiad will be: I-Chen Wu and M. Winands.

The envisaged Assistant Tournament Directors are: H. Iida and W.A. Kosters.

The ICGA headquarters organizers are: Monique Arntz and Grace Krabbenbosch.

The arrangement committee: Guido Rijndam (chair), Abdel Boujadayni and Marloes van der Nat. 


\section{5th INTERNATIONAL CONFERENCE ADVANCES IN COMPUTER GAMES (ACG 2017)}

The 15th International Conference Advances in Computer Games (ACG 2017) will be held on July 3-5, 2017, at Leiden University, the Netherlands.

Papers submitted to the conference will undergo a full peer review process, and Proceedings are expected to be published by Springer. More information can be found in the Call for Papers that has been published in January 2017. Papers are expected to have eight to ten pages, in the usual format. Exceptional papers may have 12 pages but longer papers will not be processed.

Important dates:

Paper submission deadline: March 6, 2017.

Notification of acceptance: April 3, 2017.

Camera ready papers due: May 1, 2017.

Relevant websites:

Conference website: http://acg2017.wordpress.com.

Submissions website: https://www.conftool.net/acg2017. 